\title{
RISK FACTORS OF NEURAL TUBE DEFECTS: A STUDY
}

Tara Jayant ${ }^{1}$

Abstract - Neural tube defects (NTDs) are birth defects of brain and spinal cord. The incidence of neural tube defects dates back to Ancient Egyptian times, (Obladen, 2011) when fetuses and infants with anencephaly, myelomeningocele and craniorachischisis were reported. Thomas Mc Keown and RG Record, in a series of case control studies conducted on commonly occurring major defects in 1940s, observed that factors like season and year of birth, maternal age, birth rank and socioeconomic status play important role in causing these defects. They mentioned the role of folic acid in reducing the incidence of neural tube defects (Leek, 1996). Many research findings have confirmed their work. So far, nutritional deficiency in mother, genetic factors and some environmental factors have been found to play important role in causing these defects. The present paper attempts to review the contribution of some principal risk factors in the etiology of NTDs, on the basis of studies and findings of various researchers.

Keywords- NTDs, Birth Defects, Nutritional Deficiency, Folic Acid.

\section{INTRODUCTION}

In embryos of chordates, including vertebrates, neural tube is an embryonic structure which is precursor of brain and spinal cord and forms its central nervous system. The development and closure of the neural tube is completed in about 28 days after conception. The abnormal neural tube closure, results in the development of a neural tube defect in the embryo (Imbard et al. 2013).As reported by Mitchell (2005), an average of 1 in every 1000 established pregnancies worldwide is affected with NTDs. Olney and Mulinare (1998) has recorded a geographic and temporal variation in the incidence of some major NTDs. Furthermore, Feuchtbaum et al. (1999) in their study, observed that within a specified geographical area and time period, a significant variation in the prevalence of NTDs occurs depending upon the race and ethnicity and type of NTD.

Neurulation: The process by which neural tube is formed in an embryo is called neurulation. It initiates with the development of the neural plate as a thickening of the dorsal ectoderm, followed by molding of neural plate, with the processes including convergent extension. The neural plate then curves, elevates and starts moving towards the midline. The extremities come into contact and merge together to create the neural tube, which, subsequently, gets covered by epidermal ectoderm. Closure of the cranial neural tube is considered to be vital for the appropriate development of brain, as well as initial formation of major part of the skull (Imbard et al. 2013).

In mammalian embryos, neurulation occurs in two phases: primary neurulation and secondary neurulation. These two phases occur in separate areas along the rostro-caudal axis of the embryo. The entire neural tube rostral to the caudal neuropore, is produced by primary neurulation. This process occurs in the third and fourth weeks of development. During this process, the flat layer of ectodermal cells overlying the notochord gets transformed into a hollow tube. Secondary neurulation is restricted to the tail bud region, which lies ahead the caudal neuropore. Contrary to primary neurulation, the secondary neurulation takes place by proliferation of stem cells, which leads to the formation of a rod-like condensation that subsequently undergoes cavitation. As a result of cavitation, the rod gets transformed into a tube and the lumen of this tube becomes continuous with the lumen of the tube formed during primary neurulation (Detrait et al. 2005).

\section{CLASSIFICATION OF NEURAL TUBE DEFECTS}

On the basis of embryological considerations and the presence or absence of exposed neural tissue, the NTDs can be classified as: Open NTDs and Closed NTDs. Open neural tube defects occur due to failure of primary neurulation and often include the entire central nervous system. They are characterized by presence of uncovered neural tissue which is associated with cerebrospinal fluid (CSF) leakage. Closed neural tube defects, on the other hand, arise due to defective secondary neurulation. They generally remain confined to the spine, rarely affecting the brain. They are rarer type of NTDs in which the neural tissue is not exposed and the defect is covered by the skin. The NTDs present in the cranial region include Anencephaly, Encephalocele (meningocele or meningomyelocele), Craniorachischisistotalis and Congenital dermal sinus, whereas those present in the spinal region include Spina bifida aperta (cystica), Myelomeningocele, Meningocele, Myeloschisis, Congenital dermal sinus, Lipomatous malformations (lipomyelomeningoceles), Split-cord malformations, Diastematomyelia, Diplomyelia and Caudal agenesis (Jallo,2015).

\footnotetext{
${ }^{1}$ Department of Zoology, Govt. P.G. College for Women, Panchkula, Haryana, INDIA
} 


\section{CLINICAL FEATURES OF NEURAL TUBE DEFECTS}

Clinical severity of NTDs varies greatly depending upon whether the lesion is opened or closed. The experiments of Wood and Smith (1984) on rats have shown that open neural folds undergo growth and differentiation and typically appear to bulge from the developing brain, termed exencephaly. The skull vault is not formed over the open region, which causes degeneration of exposed neural tissue, leading to manifestation of anecephaly. Open lesions like anencephaly and craniorachischisis are found to be unvaryingly lethal before or shortly after birth. Another open NTD termed as encephalocele is characterized by sac-like protrusions of the brain and covering membranes, through the openings of the skull. Encephalocele is generally associated with neurological problems if it is located in the back of the skull. Also, there are various craniofacial or other brain malformations. Hydrocephalus (excessive accumulation of cerebrospinal fluid in the brain), spastic quadriplegia (paralysis of the arms and legs), microcephaly (abnormally small head), ataxia (uncoordinated movement of the voluntary muscles, such as those involved in walking and reaching), delay in development, vision problems, retardation of mental and physical growth, and convulsions, are other abnormalities which are found associated with encephaloceles (National Institute of Neurological Disorders and Stroke, 2007). Presence of open neural folds in the spinal region causes spina bifida, in which the sclerotome-derived vertebral arches fail to cover the neuroepithelium leading to significant damage to the nerves and spinal cord (Copp et al. 2015). The children born with open spina bifida usually survive after birth, but suffer from paralysis of the lower body and learning disabilities (Chobe et al. 2014). Because bladder and bowel movements are controlled by the lowest spinal nerves, bowel and urinary disorders are very common in case of spina bifida (Centers for Disease Control and Prevention, 2011).

Closed neural tube defects are the abnormalities of fat, bone, or membranes. They may be asymptomatic in some people, but others might experience partial paralysis or other symptoms. In some cases, only a dimple or tuft of hair on the spine can be seen externally (Mc Comb \& Chen, 1996). The closed NTD termed as spina bifida occulta, is considered to be the mildest type of spina bifida. Also known as "hidden" spina bifida, it is characterized by the presence of a small gap in the spine, with no opening or sac on the back and normal nerves and spinal cord. This type of spina bifida often does not cause any disabilities and may remain undiscovered until late childhood or adulthood (National Institute of Neurological Disorders and Stroke, 2012)

\section{RISK FACTORS FOR NTDs}

The March of Dimes Global Report on Birth Defects, which details the birth prevalence rates and number of affected births in 193 countries, estimates that, 7.9 million children (6 percent of total births worldwide) are born with a serious birth defect of genetic or partially genetic origin, every year. At least 3.3 million children under five years of age die from birth defects each year and an estimated 3.2 million of those who survive may get disabled for life. According to this report, congenital heart defects $(1,040,835$ births), neural tube defects (323,904 births), the hemoglobin disorders, thalassemia and sickle cell disease (307,897 birth), Down's syndrome (217,293 births) and glucose-6-phosphate dehydrogenase (G6PD) deficiency (177,032 births) were the most common five serious birth defects of genetic or partially genetic origin in 2001.The report also mentioned that the impact of birth defects is more severe in middle- and low income countries with 94 percent of the births with serious birth defects and 95 percent of the deaths of children with theses defects (Christianson et al. 2006).

Though the exact pathogenesis of these conditions is unknown, there are numerous and complex risk factors that have constantly been recognized in various studies. In case of neural tube defects, the main risk factors which have been identified and studied can be categorized into nutritional factors, genetic factors, maternal diabetes and obesity, and use of antiepileptic drugs by pregnant women.

\section{NUTRITIONAL FACTORS}

\subsection{Maternal Folate Deficiency}

The best known risk factor for fetal NTD is maternal folate deficiency, arising from low levels of vitamin B9 (folic acid). The serum folate, red cell folate, white blood cell vitamin C, and riboflavin values in first trimester were found to be lower than normal in mothers who gave birth to infants with neural tube defects (Smithells et al. 1976). Stover in 2009 found that folate undergoes one-carbon metabolism, involving a complex network of interlinked reactions that facilitates the transfer of onecarbon groups for numerous biosynthetic pathways. Two such pathways are: formation of pyrimidine and purine bases for DNA replication during cell proliferation, and contributing the methyl groups to macromolecules like DNA, proteins and lipids (Copp et al. 2013). Research findings of Smith and Schoenwolf (1987) have shown that alteration of cell cycle causes changes in the neuroepithelial cell shape during bending of chick neural plate. This encourages the hypothesis that folate has an important role in increased cell proliferation during neural tube formation. Thus, all women who have had a pregnancy affected with NTD, can be recommended to have folic acid supplementation starting before pregnancy and all women of child bearing age should be given adequate amount of folic acid in their diet (MRC Vitamin Study Research Group, 1991).

\subsection{Maternal Vitamin B12 Deficiency}

The reduction in the incidence of NTDs after implementation of folic acid fortification by various countries suggests that sufficient intake of folate is vital for prevention of NTDs. However, some researchers have suggested, that adequate vitamin 
B12 levels might also be necessary. The investigations of Ray and Blom (2003) suggested the moderate association between low maternal B12 status and the risk of fetal NTDs. Serum vitamin B12 levels have been found low in women with neural tube defect pregnancy (Wald et al. 1996). Vitamin B12 seems to play some vital role in proper functioning of the enzyme methionine synthase that converts homocysteine to methionine (Refsum, 2001).In countries like India, where much of the population is vegetarian and known to be deficient in vitamin B12, folate alone might not have adequate benefits in preventing fetal NTDs.

\subsection{Genetic Factors}

Maximum number of NTDs is found to occur sporadically with relatively limited cases of multigenerational families (Greene and Copp, 2014). However, numerous candidate genes have been proposed for understanding the cause of human NTDs based on biochemical and developmental studies, mouse models and positional evidence. In case-control or family-based association studies, on 38 candidate genes, few have shown notable results in human populations (Boyles et al. 2005). Various researchers are of the view that, genetic factors responsible for causing NTDs could involve either folate-related or folate-independent genes. The evaluation of folate-related genes as NTD candidates has been emphasized so far (Molloy et al. 2009).Presence of genetically-determined abnormality of folate metabolism in fetuses having NTD, observed in the analysis of their primary cell lines, also supports the role of folate-related genes (Van der Put et al. 1995). The study of a number of genetic variants have shown variable results in different cohorts and populations and very few of them have been found to have a key causative effect (Human molecular genetics, 2009). The folate-related genes candidate can be further divided into three categories, namely methylation related genes, folate cycle enzymes required for nucleotide biosynthesis and genes encoding proteins required for folate transport (Greene et al. 2009).

The enzyme 5, 10-Methylenetetrahydrofolate reductase (MTHFR) is known to catalyzes the reduction of 5, 10methylenetetrahydrofolate to 5-methyltetrahydrofolate, the principal circulatory form of folate which donates carbon for the re-methylation of homocysteine to methionine (Scott and Weir, 1994). The MTHFR 677C $\rightarrow$ T polymorphism converts alanine to valine, which results in the formation of thermolabile variant of the enzyme (Kang et al. 1988). In a study by Frosst et al. (1995), patients with coronary and peripheral artery disease are stated to have reduced MTHFR activity due to presence of its thermolabile variant and plasma homocysteine levels have been found to be considerably high in individuals, homozygous for thermolabile variant of MTHFR (TT). In addition, the NTD affected people are reported to have abnormal thermolabile enzyme in homozygous condition, in DNA sample analysis conducted on people with NTDS, their parents and normal controls (Whitehead et al.1995). This was the first definite genetic abnormality which explained the association between some NTDs and elevated homocysteine levels, in Irish population.

The second important folate-dependent enzyme is methylenetetrahydrofolate dehydrogenase1 (MTHFD1). MTHFD1, commonly known as "C1-THF synthase", is a trifunctional, nicotinamide adenine dinucleotide phosphate (NADP)dependent cytoplasmic enzyme, which catalyzes biochemical reactions involving the conversion of tetrahydrofolate to the corresponding 10-formyl, 5, 10-methenyl, and 5, 10-methylene derivatives. The derivatives 10-Formyltetrahydrofolate and 5, 10-methylenetetrahydrofolate play vital role in biosynthesis of purine and pyrimidine and thus, help in biosynthesis of DNA (Brody et al. 2002).

In a studies conducted on Irish populations (Brody et al. 2002) and Italian populations (De Marco et al. 2006), it has been reported that MTHFD1 1958G > A polymorphism in heterozygous and homozygous conditions is the genetic determinant of both maternal and NTD case risk. The MTHFD1 R653Q polymorphism, which lies in the 10-formyltetrahydrofolate synthetase area of MTHFD1, causes reduced C1THF synthase activity in cell lines, which further results in reduced purine biosynthesis (Christensen et al. 2009). In addition to this, a promoter polymorphism (rs1076991C >T) in MTHFD1, that results in reduced transcriptional activity in vitro, was also found linked with NTD case and maternal risk(Carroll et al. 2009).

The third important group of candidate genes comprises those, which encode the proteins required for the transport, uptake and cellular retention of folates. These proteins include folate receptors FR $\alpha$ (Folr1 in mice), FR $\beta$ and FR $\gamma$, RFC1 (reduced folate carrier), GCPII (folyl- $\gamma$-glutamate carboxypeptidase) and FPGS (folylpolyglutamatesynthetase) (Beaudin and Stover, 2009). The studies available till date do not provide any definite evidence to show that common polymorphisms in these genes affect the folate status. No variants have been identified within the coding regions of the folate receptor genes, and the polymorphisms found in noncoding regions of FR $\alpha$ and FR $\beta$ have not brought forth any association with NTD risk (O'Learyet al. 2003). In the RFC1 gene, a common single nucleotide polymorphism (SNP) has shown an adequate relationship with NTD risk under conditions of folate deficiency, though with low penetrance level (Shaw et al. 2002). Likewise, the single polymorphism H475Y recognized in GCPII has not found to affect NTD risk in humans (Afman et al.2003).

\subsection{Maternal Diabetes And Obesity}

Since very long, maternal insulin-dependent diabetes has been connected with congenital malformations. A great majority of researchers have observed that infants of insulin-dependent diabetic mothers have two to three fold chances of getting affected with birth defects, though there is not a collective agreement (Mills, 1982). Single nucleotide polymorphism (SNPs) in maternal genes such as FTO, LEP, TCF7L2, LEPR, GLUT1 and HK1, concerned with glucose metabolism and obesity, 
may be responsible for increased vulnerability to NTDs like spina bifida (Davidson et al. 2008). Further, the pathogenesis of obesity has been reportedly found associated with variations in the fat mass and an obesity-associated gene (FTO), though, FTO may have a low-penetrance susceptibility for obesity risk and the association between FTO polymorphisms and obesity risk may vary in different ethnic groups (Peng et al. 2011). In diabetic pregnancies, the fetuses receiving excessive amount of glucose at the time of neural tube formation, may not be capable of controlling these elevated levels and consequently develop congenital malformations ( $\mathrm{Li}$ et al. 2007).

Maternal obesity, with body mass index (BMI) of $\geq 30$, is another factor that is known to increase the risk of development of NTD in the embryo, twice or more (Shaw et al. 2000). On the basis of a geographically based case-control study conducted on women living in California and Illinois, Waller et al. in 1994 suggested that offspring of obese women have higher risk of neural tube defects and several other congenital malformations. Another population-based case-control study by Watkins et al. (2003), on some particular major birth defects, confirmed the formerly ascertained relationship between spina bifida and prepregnancy maternal obesity and found that maternal obesity is linked with omphalocele, heart defects, and multiple abnormalities among the embryos. Ray et al. (2005), also emphasized that there is increased risk of NTDs in infants of obese women even if they are using folic acid periconceptionally.

\subsection{Maternal Use Of Antiepileptic Drugs (Aeds)}

The use of antiepileptic drugs (AEDs) by pregnant women has been associated with chronic teratogenic effects on fetus, the most common of which are congenital heart diseases, cleft lip, urinogenital defects, and neural tube defects (Meador, 2008).Valproic acid and Carbamazepine, the two main anticonvulsant medications which are presently in use, have been found to cause these defects (Rose and Mennuti, 2009). In a review of published cohort studies, 14 major congenital malformations have been identified, whose risk increases when the pregnant women undergoes valproic acid monotherapy during the first trimester as compared with no exposure to antiepileptic drugs during the first trimester. Out of these, the risk for spina bifida, was found to be 12 or 16 times higher, depending on the control group used (Jentink et al. 2010). Also, valproic acid is the only AED for which the increase in risk of birth defect depends upon dosage taken, as compared to other AEDs. This has been clearly observed in cases where the dose of valproic acid is above 800-1000 mg/day (Perucca, 2005). Carbamazepine (CBZ) is another antiepileptic drug that is used mainly for the treatment of epileptic convulsions. In an investigation based on the data pooled from prospective studies which involved 1255 cases of prenatal exposure to CBZ therapy, the higher incidence of congenital abnormalities, mainly neural tube defects, cardiovascular and urinary tract defects, and cleft palate has been reported (Matalon et al. 2002). In other study on NTDs, performed by Rosa (1991), it has been observed that $1 \%$ of the infants who had CBZ exposure before birth, got affected with spina bifida. Furthermore, the teratogenic effect gets increased when a combination of CBZ with other antiepileptic drugs is used, in comparison to CBZ monotherapy (Matalon et al. 2002).

\section{CONCLUSION}

NTDs are congenital birth defects which are one of the major causes of neonatal deaths and lifelong disabilities among children worldwide. The prevalence of NTDs is considered to be more in low income countries and developing countries like India. Though maternal folic acid deficiency has been identified as key causative factor behind NTDs and mandatory folic acid fortification programs in various countries worldwide has resulted in reduced incidence of NTDs, the role of genetic, epigenetic and environmental factors has been found instrumental. Thus, the NTDs comprise a varied group of malformations which occur due to cumulative impact of multiple causative factors, rather than simple vitamin deficiency disorders. Certainly, there are excellent studies that have been carried out on important risk factors involved in etiology of NTDs, the scope for identifying the correlation between various risk factors still exists. Further exploration in this area can help in better understanding of the cause of specific NTDs and thus framing the preventive strategies.

\section{REFERENCES}

[1]. Afman LA, Trijbels FJ, Blom HJ. The H475Y polymorphism in the glutamate carboxypeptidase II gene increases plasma folate without affecting the risk for neural tube defects in humans. J Nutr. 2003; 133:75-77.

[2]. Agopian AJ, Tinker SC, Lupo PJ, Canfield MA, Mitchell LE. Proportion of neural tube defects attributable to known risk factor s. Birth Defects Res. A Clin. Mol. Teratol. 2013; 97(1):42-46.

[3]. Beaudin AE, Stover PJ. Insights into metabolic mechanisms underlying folate-responsive neural tube defects: a minireview. Birth Defects Res. A Clin Mol. Teratol. 2009; 85:274-284.

[4]. Boyles AL, Hammock P, Speer MC. Candidate gene analysis in human neural tube defects. American Journal of Medical Genetics. Part C. Seminars in medical genetics.2005 May; 135C (1): 9-23.

[5]. Carroll N, Pangilinan F, Molloy AM, Troendle J, Mills JL, Kirke PN, Brody LC, Scott JM , Parle-McDermott A. Analysis of the MTHFD1 promoter and risk of neural tube defects. Hum. Genet. 2009; 125:247-256.

[6]. Christensen B and Rosenblatt DS, Effects of folate deficiency on embryonic development, Bailliere's Clinical Haematology. 1995 Sep; 8(3): 617-37.

[7]. Christensen KE, Rohlicek CV, Andelfinger GU, Michaud J, Bigras JL, Richter A, Mackenzie RE, Rozen R. The MTHFD1 p.Arg653Gln variant alters enzyme function and increases risk for congenital heart defects. Hum. Mutat. 2009; 30:212-220.

[8]. Christianson A, Howson CP, Modell CB, (2006) March of Dimes Global Report on Birth Defects: The Hidden Toll of Dying and Disabled Children. The March of Dimes. 
[9]. Copp AJ, Adzick NS, Chitty LS, Fletcher JM, Holmbeck GN., and Shaw GM, Spina Bifida, Nature Reviews Disease Primers,2015; 1: 15007.

[10]. Copp AJ, StanierP and Greene NDE, Neural tube defects - recent advances, unsolved questions and controversies, Lancet Neurol. 2013 Aug; 12 (8): 799-810.

[11]. Davidson CM, Northrup H, King TM, Fletcher JM, Townsend I, et al. Genes in glucose metabolism and association with spina bifida. Reprod Sci. 2008; 15(1): 51-58.

[12]. Detrait ER, George TM, Etchevers HC, Gilbert JR, Vekemans M, Speer MC. Human neural tube defects: developmental biology, epidemiology, and genetics. Neurotoxicology and Teratology, 2005; 27(3): 515-524.

[13]. Feuchtbaum LB, Currier RJ, Riggle S, Roberson M, Lorey FW, Cunningham GC. 1999. Neural tube defect prevalence in California (1990-1994): Eliciting patterns by type of defect and maternal race/ethnicity. Genet Testing 3: 265-272.

[14]. Greene NDE, Stanier P and Copp AJ. Genetics of human neural tube defects. Human molecular genetics.2009 Oct15; 18(R2): R113-R129.

[15]. Greene NDE and CoppAJ. Neural Tube Defects, Annu Rev Neurosci. 2014; 37: 221-242.

[16]. I Leek. McKeown, Record and epidemiology of malformations, Paediatric and Perinatal Epidemiology. Vol.10 Issue 1, pages 2-16, January 1996.

[17]. Imbard A, Benoist JF, Blom HJ. Neural tube defects, folic acid and methylation. Int J Environ Res Public Health. 2013, 10(9): 4352-4389.

[18]. Jentink J, Loane MA, Dolk H, et al. Valproic acid monotherapy in pregnancy and major congenital malformations. N Engl J Med 2010; 362:2185-93.

[19]. Juriloff DM, Harris MJ. Hypothesis: the female excess in cranial neural tube defects reflects an epigenetic drag of the inactivating X chromosome on the molecular mechanisms of neural fold elevation. Birth Defects Res. A Clin. Mol. Teratol. 2012b;94(10):849-55.

[20]. Li R, Thorens B, Loeken MR. Expression of the gene encoding the high-Km glucose transporter 2 by the early postimplantation mouse embryo is essential for neural tube defects associated with diabetic embryopathy. Diabetologia. 2007;50:682-689.

[21]. Mc Comb JG, \& Chen TC.(1996). Closed spinal neural tube defects. In: GT Tindall, PR Cooper, \& DL Barrow (Eds.), The practice of neurosurgery (pp. 2754-2777). Baltimore: Williams \& Wilkins.

[22]. Mitchell LE. Epidemiology of neural tube defects. Am J Med Genet C Semin Med Genet. 2005; 135: 88-94.

[23]. O'Leary VB, Mills JL, Kirke PN, et al. Analysis of the human folate receptor beta gene for an association with neural tube defects. Mol Genet Metab. 2003; 79: 129-133.

[24]. Obladen M. Cats, frogs, and snakes: early concepts of neural tube defects. J Child Neurol. 2011; 26: 1452-61.

[25]. Olney R, Mulinare J. 1998. Epidemiology of neural tube defects. Ment Retard Dev Disabil Res Rev 4: 241-246.

[26]. Peng S, Zhu Y, Xu F, et al. FTO gene polymorphisms and obesity risk: a meta-analysis. BMC Med. 2011; 9:71.

[27]. Perucca E. Birth defects after prenatal exposure to antiepileptic drugs. Lancet Neurol.2005 Nov; 4(11): 781-6.

[28]. Prevention of neural tube defect: results of the Medical Research Council Vitamin Study. MRC Vitamin Study Research Group. Lancet 1991 Jul 20 ; 338 (8760): 131-7.

[29]. Ray JG, Blom HJ. Vitamin B12 insufficiency and the risk of fetal neural tube defects. QJM. 2003 Apr; 96(4): 289-95.

[30]. Ray JG, Wyatt PR, Vermeulen MJ, Meier C, Cole DEC. Greater maternal weight and the ongoing risk of neural tube defects after folic acid flour fortification. Obstet Gynecol. 2005; 105(2): 261-65.

[31]. Refsum H. Folate, vitamin B12 and homocysteine in relation to birth defects and pregnancy outcomes. The British Journal of Nutrition.2001 May; 85 Suppl 2: S109-13.

[32]. Shaw GM, Lammer EJ, Zhu H, et al. Maternal periconceptional vitamin use, genetic variation of infant reduced folate carrier (A80G), and risk of spina bifida. Am J Med Genet. 2002; 108:1-6.

[33]. Shaw GM, Todoroff K, Finnell RH, Lammer EJ. Spina bifida phenotypes in infants or fetuses of obese mothers. Teratology. 2000; 61(5):376-81.

[34]. Smith JL, Schoenwolf GC. Cell cycle and neuroepithelial cell shape during bending of chick neural plate. The Anatomical Record. 1987 Jun; 218(2): 196-206.

[35]. Stover PJ. One carbon metabolism - genome interactions in folate associated pathologies. The Journal of Nutrition.2009 Dec; 139 (12): $2402-5$.

[36]. Wald NJ, Commentary: A Brief History of Folic acid in Prevention of Neural Tube Defects, International Journal of Epidemiology. 2011Oct; 40(5):1154-1156.

[37]. Wald NJ, Hackshaw AD, Stone R, Sourial NA. Blood folic acid and vitamin B12 in relation to neural tube defects. Br J Obstet Gynaecol.1996 Apr; 103(4): 319-24.

[38]. Waller DK, Mills JL, Simpson JL, et al. Are obese women at higher risk for producing malformed offspring? Am J Obstet Gynecol. 1994; 170: 541548.

[39]. Watkins ML, Rasmussen SA, Nonein MA, et al. Maternal obesity and risk for birth defects. Pediatrics. 2003; 111: 1152-1158.

[40]. Whitehead AS, Gallagher P, Mills JL, Kirke PN, Burke H, Molloy AM, Weir DG, Shields DC, Scott JM (1995) A genetic defect in 5,10methylenetetrahydrofolate reductase in neural tube defects. Q J Med 88:763-766.

[41]. Wood LR, Smith MT. 1984. Generation of anencephaly: 1.Aberrant neurulation and 2. Conversion of exencephaly to anencephaly. J Neuropathol Exp Neurol 43: 620-633.

[42]. Brody LC, Conley M, Cox C, Kirke PN, McKeever MP, Mills JL, Molloy AM, O’Leary VB, Parle-McDermott A., Scott JM, et al. A polymorphism, $\mathrm{R} 653 \mathrm{Q}$, in the trifunctional enzyme methylenetetrahydrofolatedehydrogenase/ methenyltetrahydrofolatecyclohydrolase/ formyltetrahydrofolatesynthetase is a maternal genetic risk factor for neural tube defects: report of the Birth Defects Research Group. Am. J. Hum. Genet. 2002;71:1207-1215.

[43]. Centres for Disease Control and Prevention (2011), Spina bifida.

[44]. ChobePaayal, Uchit Ganesh and DondeShaantanu, Indian Perspective on C linical Aspects, Usage and Guidelines of Folic Acid, J ObstetGynaecol India. 2014 Oct; 64(5):328-331.

[45]. De Marco P, MerelloE, Calevo MG, Mascelli S, Raso A, Cama A, Capra V. Evaluation of a methylenetetrahydrofolate-dehydrogenase 1958G>A polymorphism for neural tube defect risk. J. Hum. Genet. 2006;51:98-103

[46]. Frosst P, Blom HJ, Milos R, Goyette P, Sheppard CA, Matthews RG, Boers GJH, Den Heijer M, Kluijtmans LAJ, Van den Heuvel LP, et al. A candidate genetic risk factor for vascular disease: a common mutation in methylenetetrahydrofolateredu ctase. Nat. Genet. 1995;10:111-113.

[47]. Human molecular genetics.2009 Oct15; 18(R2): R113-R129.

[48]. Jallo George I. Neural Tube Defects, Medscape, 2015 Dec. 
[49]. Kang S-S, Wong PWK, Zhou J, Sora J, Lessick M, Ruggie N, Grcevich G (1988) Thermolabilemethylenetetrahydrofolatereductase in patients with coronary artery disease. Metabolism 37:611-613.

[50]. Matalon S, Schechtman S, Goldzweig G, Ornoy A. The teratogenic effect of carbamazepine: a meta-analysis of 1255 exposures. ReprodToxicol. 2002;16:9-17.

[51]. Meador KJ. Effects of in utero antiepileptic drug exposure. Epilepsy Curr. 2008;8:143-147.

[52]. Mills JL. Malformations in infants of diabetic mothers. Teratology. 1982;25:385-394.

[53]. Molloy AM, Brody LC, Mills JL, Scott JM, Kirke PN. The search for genetic polymorphism in the homocysteine/folate pathway that contribute to the etiology of human neural tube defects. Birth Defects Res. A Clin. Mol. Teratol.2009; 85: 285-294.

[54]. National Institute of Neurological disorders and Stroke (2007), encephaloceles information page.

[55]. National Institute of Neurological disorders and Stroke (2012), spina bifida fact sheet.

[56]. Rosa F. Spina bifida in infants of women treated with carbamazepine during pregnancy. N Engl J Med. 1991;324:674-677.

[57]. Rose N, Mennuti, M, Glob. libr. women's med., (ISSN: 1756-2228) 2009; DOI 10.3843/GLOWM.10224.

[58]. Scott JM, Weir DG (1994) Folate/vitamin B12 inter-relationships. Essays Biochem 28:63-72.

[59]. SmithellesRW, SheppardS and SchorahCJ. Vitamin deficiencies and neural tube defects. Archives of disease in childhood.1976 Dec;51(12): 944-950.

[60]. Van der Put NMJ., Steegers-Theunissen RPM, Frosst P, Trijbels FJM, Eskes TKAB, Van den Heuvel LP, Mariman ECM, Den Heyer M, Rozen R, Blom HJ. Mutated methylenetetrahydrofolatereductase as a risk factor for spina bifida. Lancet. 1995;346:1070-1071. 